\title{
Ensaio biomecânico para determinação do diâmetro de barra conectora de polimetilmetacrilato em fixador esquelético externo tipo Ia no úmero de suínos
}

\author{
[Biomechanical test to determination the diameter of the polymethylmethacrylate bar in external \\ skeletal fixator type Ia in swine humerusi] \\ B. Schmitt ${ }^{1}$, G.M.C. Serafini ${ }^{1}$, R.N. Libardoni ${ }^{2}$, F.W. Souza ${ }^{3}$, J.P.S. Feranti ${ }^{4}$, C.R. Cauduro ${ }^{5}$, \\ A.S. Amaral ${ }^{6}$, M.V. Brun ${ }^{6}$ \\ ${ }^{1}$ Universidade Regional do Noroeste do Estado do Rio Grande do Sul - Ijuí, RS \\ ${ }^{2}$ Faculdade de Agronomia e Medicina Veterinária - Universidade de Passo Fundo - Passo Fundo, RS \\ ${ }^{3}$ Departamento de Medicina Veterinária - UFAl - Viçosa, AL \\ ${ }^{4}$ Universidade da Região da Campanha - Alegrete, RS \\ ${ }^{5}$ Colégio Técnico Industrial - UFSM - Santa Maria, RS \\ ${ }^{6}$ Centro de Ciências Rurais - UFSM - Santa Maria, RS - Bolsista do CNPq - Brasil (308019/2015-6; 200346/2017-2)
}

\section{RESUMO}

Fraturas ósseas podem ser corrigidas com a utilização de fixadores esqueléticos externos (FEE), método de estabilização bastante comum. Para tanto, têm-se utilizado barras conectoras de polimetilmetacrilato (PMMA) sem critério de diâmetro, as quais podem quebrar, se ficarem muito delgadas, ou ocasionar incômodo, quando muito pesadas e volumosas. O objetivo deste trabalho foi testar, por meio de ensaio biomecânico de compressão axial e flexão, qual é o diâmetro ideal da barra conectora de PMMA, correlacionado com o diâmetro ósseo para utilização em FEE tipo Ia. Utilizaram-se 24 úmeros para se realizarem medidas de comprimento, diâmetro, circunferência e ensaios biomecânicos. Após, foram confeccionadas barras de 1,5 vezes a média do diâmetro ósseo (grupo I), do mesmo diâmetro ósseo (grupo II) e de 0,5 vezes o diâmetro (grupo III). Com os resultados obtidos ao se compararem os valores dos ossos com os dos grupos II e III, verificou-se que as barras conectoras do grupo II mostraram-se mais resistentes do que o tecido ósseo no ensaio de compressão. No ensaio de flexão, os ossos resistiram mais quando comparados aos grupos II e III, sendo 4,3 vezes mais resistentes do que o grupo III nesse mesmo ensaio mecânico. Os resultados permitem um direcionamento para confecção de barras considerando-se o diâmetro ósseo como referência.

Palavras-chave: suínos, resina acrílica, resistência, compressão axial, flexão

\begin{abstract}
Bone fractures can be corrected from external skeletal fixators (ESF) in a fairly common internal stabilization method, in which connector bars polymethylmethacrylate (PMMA) is used. PMMA is used without criterion of diameter, and it can break if it is too thin or too heavy. It can be uncomfortable when bulky. The aim of this study was to test, through biomechanical axial compression and bending which is the ideal connector bar diameter PMMA, correlated to bone diameter for use in type Ia ESF. Twenty-four humerus were used to make measurements of length, diameter, circumference, and biomechanical testing. After the bars confected with 1.5 times the average diameter of the bone (group I), the same diameter (group II) and 0.5 times the diameter of the bone (group III). With the obtained results, using GII and GIII results, it was observed that the connector bars in group II were more resistant than the bones in the compression test. In the bending test, the bones resisted flexion strength when compared to group III and the group II was 4.3 times more resistant than group III in the same mechanical test. The results allow a direction for making bars considering bone diameter as a reference.
\end{abstract}

Keywords: swine acrylic resin, resistance, axial compression, bending

Recebido em 2 de dezembro de 2016

Aceito em 25 de agosto de 2017

E-mail: bernardoschmitt@msn.com 


\section{INTRODUÇÃO}

Apesar do seu aspecto aparentemente inerte, os ossos são estruturas altamente dinâmicas, em constante formação, reabsorção, reparação e manutenção da homeostasia (Castania, 2002; Vasseur, 2003; Judas, 2012). Ocorre fratura em ossos quando a carga aplicada sobre determinada região do tecido ósseo supera sua capacidade de resistência (Schmaedecke, 2007). Muitas vezes a fratura acompanha diferentes graus de lesão dos tecidos moles, que podem causar possíveis perturbações na irrigação sanguínea e até mesmo a perda da função locomotora (Piermattei et al., 2006).

Fixadores esqueléticos externos (FEE) são frequentemente utilizados como método de estabilização de fratura, devido a sua versatilidade e facilidade de aplicação (Rocha, 2008). O FEE é um método que consiste na inserção de pinos que não ultrapassem $20 \%$ do diâmetro do osso, passando pela pele, pelos tecidos moles e pelas corticais ósseas (Egger, 1998). Externamente, os pinos são fixados por hastes ou barras conectoras de natureza metálica ou de resina acrílica autopolimerizante de polimetilmetacrilato - PMMA (Dias e Padilha Filho, 2009).

Os FEE são indicados para fraturas de ossos longos, osteotomia corretiva, artrodese, fraturas expostas, fraturas por arma de fogo e imobilização articular temporária (Johnson, 2008). Os FEE tipo Ia (unilateral-uniplanar) são conhecidos como "meios pinos", os quais penetram as duas corticais ósseas (mas não se insinuam do lado oposto do membro), possuem uma única barra conectora e são utilizados geralmente na superfície medial da tíbia e do rádio e na superfície lateral do fêmur e do úmero (Egger, 1998; Marcellin-Little, 2003; Piermattei et al., 2006; Johnson, 2008). Barras conectoras de acrílico em FEE tornaram-se comuns na medicina veterinária pelo baixo custo, pela facilidade de aplicação, plasticidade e leveza (Rocha, 2008).

O PMMA é uma resina termofixa rígida, que não amolece após o aquecimento e que geralmente é insolúvel e infusível. O PMMA é muito utilizado na fabricação de próteses dentárias, após a mistura de um componente líquido (monômero) com um componente sólido (polímero), originando a resina acrílica. Durante a polimerização, ocorre a liberação de calor, por meio da reação exotérmica que acontece nos últimos dois a três minutos do ciclo de secagem e pode ultrapassar os $100^{\circ} \mathrm{C}$ (Flo et al., 2009).

Uma coluna conectora de PMMA com 19mm de diâmetro se torna mais resistente que uma barra conectora de Kirshner-Ehmer de aço com 4,8mm de diâmetro. A barra conectora, de resina acrílica, deve ser resistente às quatro forças fisiológicas atuantes no osso: compressão axial, tensão axial, flexão e torção (Hulse e Hyman, 2003).

Ensaios mecânicos têm o objetivo de determinar as propriedades dos materiais. Existem basicamente dois tipos de ensaios: os destrutivos e os não destrutivos. Os destrutivos provocam a ruptura ou inutilização do material. Nesse grupo, destacam-se os ensaios de tração, impactação, flexão, torção, fadiga e compressão. Nos não destrutivos, utilizam-se o raio-x e o ultrassom, por exemplo, para se determinarem propriedades físicas ou mecânicas (Souza, 1974; Amendola et al., 2008). O comportamento mecânico do osso em situações fisiológicas é similar ao comportamento de mesma natureza de objeto elástico (Cowin, 1999).

Em ensaio de compressão mecânica, a força é compressiva e o corpo de prova se contrai ao longo da direção da tensão, construindo o diagrama tensão-deformação, o qual promove esforço uniaxial, sofrendo deformação elástica e, na maioria das vezes, deformação plástica (Garcia et al, 2000a).

O ensaio de flexão em três pontos consiste em uma barra apoiada em dois pontos extremos com aplicação de carga no centro da distância entre os apoios, ou seja, existem três pontos de carga (Garcia et al, 2000b). O ensaio de flexão é o mais importante em biomecânica, pois provoca encurvamento de um corpo de prova até sua ruptura, fornecendo dados quantitativos de deformação e força da amostra testada (Cordey, 2000).

Como não se dispõe de uma relação métrica entre o diâmetro da barra conectora de PMMA com o diâmetro do osso envolvido para a confecção de barra, a qual possa permitir resistência similar ou superior ao tecido ósseo ao 
se utilizar fixador esquelético tipo Ia, o presente trabalho objetivou testar, por meio de ensaios biomecânicos de compressão axial e flexão, qual seria o diâmetro ideal da barra conectora de PMMA para FEE do tipo supracitado, correlacionando o diâmetro da barra com o diâmetro do osso envolvido.

\section{MATERIAL E MÉTODOS}

Foram utilizados 24 úmeros frescos de suínos, provenientes do abatedouro Avisui da cidade de Santa Maria - RS, abatedouro com serviço de inspeção municipal (SIM), com excelente qualidade, procedência e principalmente sanidade dos animais abatidos. Como foram utilizadas peças de abatedouro onde existe SIM, não houve necessidade da Comissão de Ética no Uso de Animais (Ceua - UFSM) avaliar este projeto, pois utilizou-se material biológico de animais sadios, já fiscalizados, que foram abatidos na rotina normal do frigorífico. Realizou-se a dissecação completa dos tecidos moles que circundavam os ossos, sendo mantidos refrigerados. Esses ossos serviram para determinar a circunferência média no ponto de menor circunferência da diáfise e $\quad$ o seu comprimento médio.

Em cada osso, foram obtidas três medições repetidas, com fita métrica, do comprimento e circunferência: considerou-se o comprimento, a medida desde o tubérculo maior até o fim do côndilo lateral do úmero e a média aritmética oriunda dos valores individuais dessa variável. $\mathrm{O}$ valor médio desse último parâmetro $(X)$ foi usado para definir o comprimento final da barra conectora. A média da circunferência foi obtida pela média aritmética dos valores individuais tomada três vezes na região diafisária distal, onde se encontra menor circunferência. A medida do diâmetro foi obtida por meio da fórmula $D=C / \pi$, em que: " $\mathrm{D}$ " é o diâmetro, "C" circunferência e " $\pi$ " a constante 3,14 .

Com base no valor de diâmetro médio dos ossos $(Y=2,6 \pm 0,1 \mathrm{~cm})$, foram criados três grupos experimentais, em que o grupo I teve 10 barras de PMMA com comprimento $X$ e diâmetro 1,5 $Y$; o grupo II, 10 barras de PMMA com comprimento $X$ e diâmetro $Y$; e o grupo III, 10 barras de PMMA com comprimento $X$ e diâmetro $0,5 Y$.

Utilizaram-se moldes de PMMA para acomodar os ossos no ensaio de compressão, impedindo que ocorresse movimentação durante os testes. Já nos grupos de PMMA, utilizaram-se moldes de canos de PVC com um metro de comprimento e nos diâmetros condizentes a cada grupo. Para a confecção das barras de acrílico, misturou-se o líquido ao pó nas proporções estabelecidas pelo fabricante e, assim que a homogeneização foi concluída (em até 30 segundos), o conteúdo, ainda em fase líquida, foi despejado em moldes inclinados em $30^{\circ}$, com uma das pontas fechadas, os quais foram submersos individualmente em tubo de dois metros de altura por $12 \mathrm{~cm}$ de diâmetro cheio d'água, em temperatura ambiente de $25^{\circ} \mathrm{C}$, onde ficaram por 12 minutos até seu resfriamento completo. Após 24 horas, as barras foram retiradas dos moldes e cortadas no comprimento padrão de $17,7 \mathrm{~cm}$. Mais tarde, nos primeiros ensaios pilotos, observou-se o aparecimento do efeito de flambagem nos ensaios de compressão devido ao comprimento excessivo das barras. Por isso, foi necessário reduzir o comprimento das barras para $8 \mathrm{~cm}$, a fim de aumentar a confiabilidade dos ensaios e, assim, tornar o comportamento do material mais próximo da realidade.

Foram executados ensaios de compressão e flexão em local fechado, com padronização de temperatura, umidade e velocidade de execução dos ensaios em todos os grupos. Nos úmeros, testaram-se 12 ossos para cada ensaio (Fig. 1A a 1C) e nas barras de cada grupo com cinco barras para cada ensaio (Fig. 2A a 2D). Com a máquina EMIC com capacidade de compressão/flexão de até $100 \mathrm{kN}$ (quilonewtons), coletaram-se os dados da força gerada em Newtons necessária para romper os corpos de prova (Fig. 3), ou até perda da resistência do material (Fig. 4). Os dados do grupo I foram excluídos da análise estatística por não apresentarem secagem completa com a metodologia empregada, pois essa condição acarretou ampla variação nos resultados dos ensaios mecânicos. 
Schmitt et al.
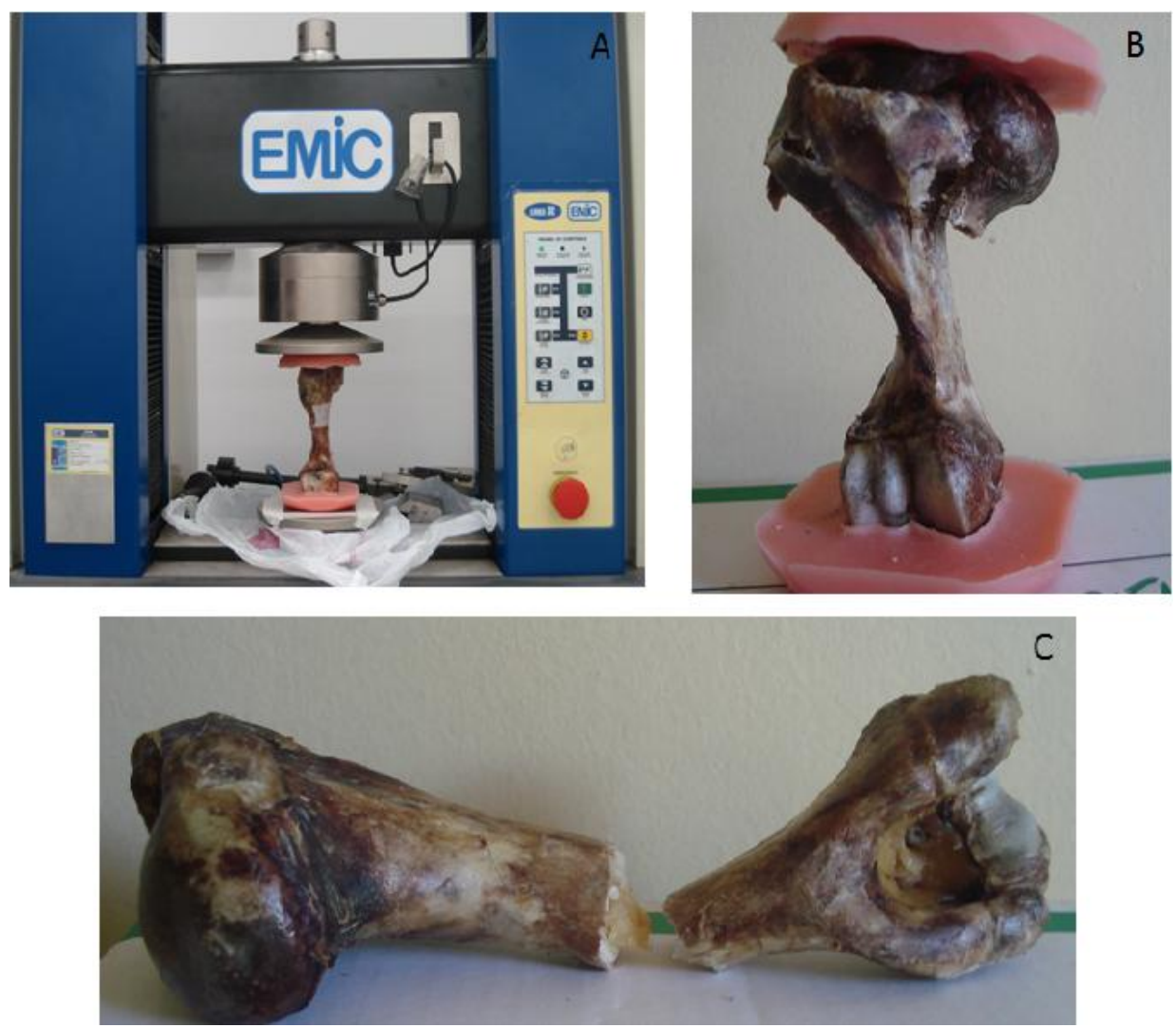

C

Figura 1. Em A, imagem durante o ensaio de compressão em úmero fresco de suíno. Em B, imagem do osso com fratura metafisária após compressão. Em C, fratura na diáfise umeral no ensaio de flexão.
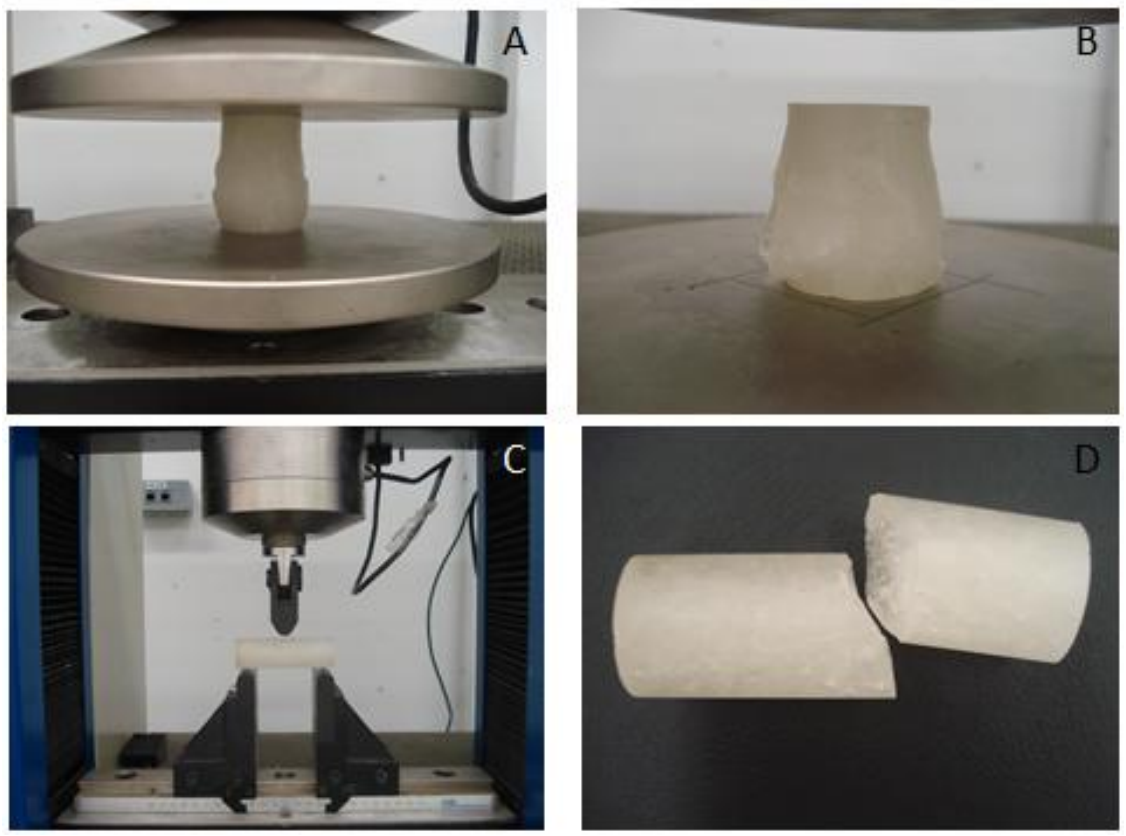

Figura 2. Em A, ensaio de compressão de barras de PMMA. Em B, deformação plástica após compressão. Em C, ensaio de flexão. Em D, ruptura do corpo de prova após flexão. 


\section{Ensaio de Flexão}

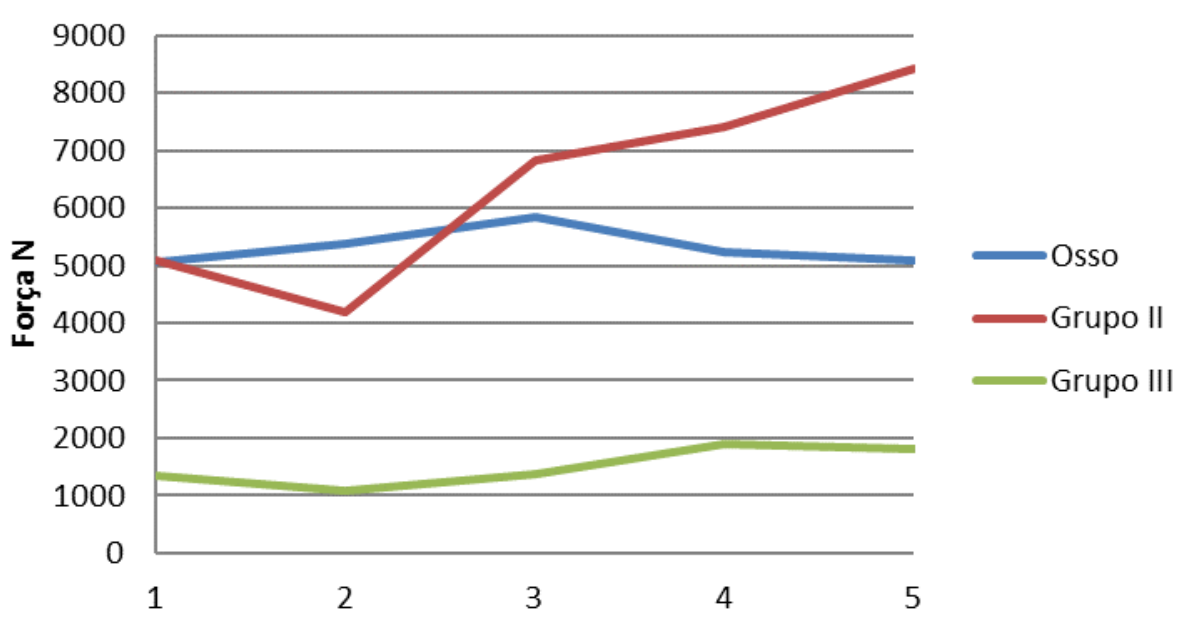

Figura 3. Ensaio de flexão considerando os valores de resistência (em Newtons) de barras de polimetilmetacrilato (PMMA) de diferentes diâmetros e de úmeros de suínos - comportamento dos ossos, grupo II (1,0 vez o diâmetro dos úmeros de suínos) e grupo III (0,5 vezes o diâmetro dos úmeros de suínos).

\section{Ensaio de Compressão}

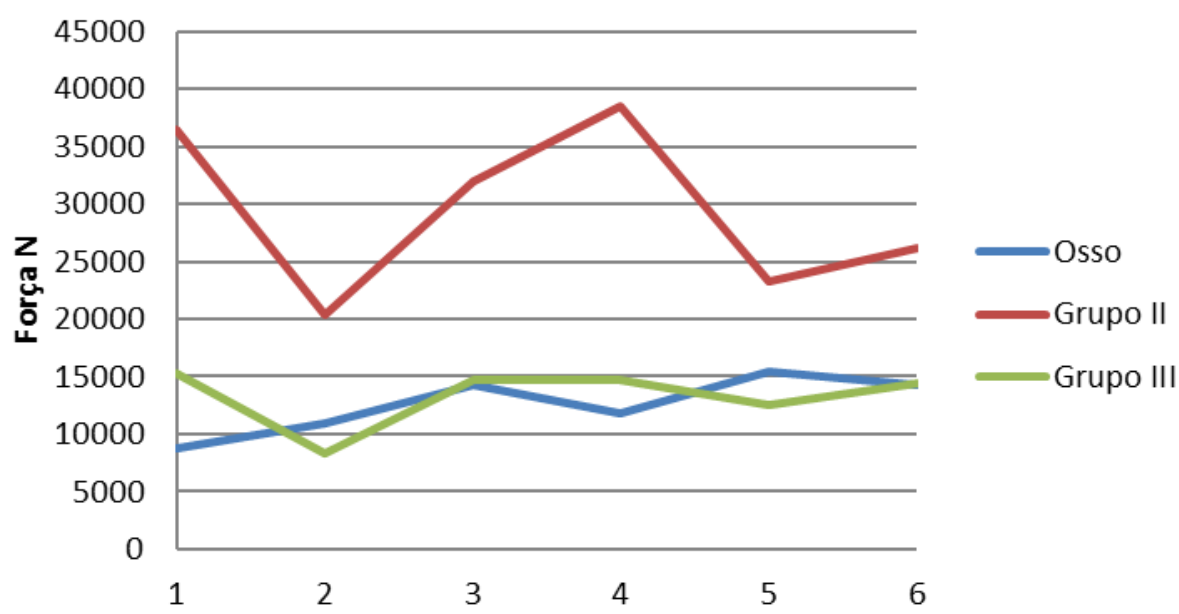

Figura 4. Ensaio de compressão considerando os valores de resistência (em Newtons) de barras de polimetilmetacrilato (PMMA) de diferentes diâmetros e de úmeros de suínos - comportamento dos ossos, grupo II (1,0 vez o diâmetro dos úmeros de suínos) e grupo III ( 0,5 vezes o diâmetro dos úmeros de suínos).

O teste estatístico utilizado foi a análise de variância (ANOVA) por meio do teste de Kruskal-Wallis, seguido por procedimentos de comparações múltiplas pareadas (Método de
Dunn), com nível de significância de 5\% para a comparação das forças geradas entre os grupos de PMMA e os ossos. 


\section{RESULTADOS E DISCUSSÃO}

Os ossos foram coletados no mesmo dia do abate, dissecados e mantidos em refrigeração para que, no dia seguinte, fossem realizados os ensaios biomecânicos, com o material ainda fresco, assemelhando o mais próximo possível do paciente ortopédico vivo. Esse cuidado atende às recomendações de An et al. (2000), os quais citam que o melhor resultado de um teste biomecânico com ossos será obtido quando houver planejamento com detalhes que incluem a fonte de ossos, os procedimentos de coleta, os métodos de estocagem, a preparação das amostras e os testes propriamente ditos.

Houve uma preocupação para que os ensaios ocorressem com a mesma máquina, no mesmo dia e na mesma sala. Padronizou-se a temperatura ambiente $\left(24^{\circ} \mathrm{C}\right)$, o posicionamento das amostras, o tamanho, a forma e a velocidade dos ensaios $(0,5 \mathrm{~cm} / \mathrm{min})$. Também foi preciso definir quantas amostras eram necessárias para realizar a estatística do trabalho a fim de que a obtenção de dados fosse fidedigna, o que torna as amostras representativas. Segundo Garcia et al, (2000b), os resultados fornecidos podem variar com a temperatura, a velocidade de aplicação da carga e os defeitos superficiais. Já An et al. (2000) consideram que o tamanho e a quantidade de amostras a serem testadas são, sem dúvida, os dois fatores mais importantes quando se quer realizar um ensaio mecânico.

Não houve preocupação em identificar a qual membro o osso pertencia, se ao direito ou ao esquerdo, pois acredita-se que não há interferência nos ensaios mecânicos. Esse fato já fora constatado por Schmaedecke (2007) em ensaios biomecânicos com ossos de cães.

Durante os ensaios de compressão, observou-se, no final de cada ensaio, que os corpos de prova apresentavam deformação plástica, sem que retornassem à sua forma original. Tal fato está de acordo com Garcia et al, (2000a), que observou que, no ensaio de compressão mecânica, a força é compressiva e o corpo de prova se contrai ao longo da direção da tensão (construindo o diagrama tensão-deformação), o qual promove esforço uniaxial, sofrendo deformação elástica e, na maioria das vezes, deformação plástica.
No presente trabalho, utilizou-se uma única marca de PMMA, buscando-se reduzir o erro experimental, porque Souza et al. (2010) testaram 13 marcas diferentes de PMMA e observaram diferenças quanto à resistência mecânica à tração e à flexão por apresentarem diferentes fórmulas do produto.

Não foi observada, nos testes de flexão dos ossos, a deformação plástica, enquanto na compressão, sim. Nos testes de compressão, a ruptura ocorreu em 83,3\% dos casos no mesmo local, na porção metafisária proximal (região de tubérculo maior). Em 100\% dos testes de flexão, houve fratura na porção diafisária média do úmero. Esses resultados estão de acordo com Souza et al. (2009), os quais citam que as propriedades mecânicas não são iguais em todas as direções. Os locais de maiores concentrações de minerais (diáfise) apresentam maior dureza e menor elasticidade, enquanto regiões de osso esponjoso (epífises e metáfises) possuem menor dureza e maior elasticidade. Ainda, Dalmolin et al. (2013) comentam que os ossos são mais resistentes na orientação longitudinal do que tangencial ou radial, fato confirmado neste trabalho, já que a média na compressão axial foi de $11624,7 \pm 2876,49 \mathrm{~N}$, enquanto na flexão a média foi de $4801,25 \pm 886,69 \mathrm{~N}$, ou seja, a resistência do osso à compressão foi duas vezes maior que a dos ossos nos ensaios de flexão.

Verificou-se a ruptura do corpo de prova nos úmeros no ensaio de compressão, resultado que está de acordo com Schwarz (1996), o qual cita que, após a deformação plástica, ao se continuar a aplicação da carga no osso, obtém-se a ruptura do corpo de prova. Já as barras de PMMA no teste de compressão apresentaram apenas deformação plástica, sem provocarem sua quebra. Segundo Garcia et al, (2000a), isso ocorre pelas propriedades físicas desse polímero, o qual provoca deformação sem ruptura quando submetido ao esforço compressivo.

Já na flexão das barras, não se pode ver a deformação plástica, pois, de acordo com Souza et al. (2009), a deformação plástica pode ocorrer em um período de tempo muito curto e próximo ao ponto de ruptura do material, ou quando a velocidade do ensaio estiver muito rápida.

Forças axiais de compressão ocorrem ao longo do eixo longitudinal do osso, produzindo 
compressão (Schwarz, 1996). Quando essa força for excêntrica, provoca uma tensão de flexão, tornando-se mais importante que somente a compressão concêntrica. Isso, por sua vez, provoca o fenômeno de flambagem, considerada uma instabilidade elástica, perdendo a estabilidade sem que tenha atingido a sua tensão máxima de ruptura (Cordey, 2000). Esse fenômeno ocorreu nos primeiros testes pilotos, porque a área de secção transversal era menor que $\mathrm{o}$ seu comprimento. $\mathrm{O}$ problema foi resolvido diminuindo-se $55 \%$ do comprimento de todas as barras de $17,7 \mathrm{~cm}$ para $8 \mathrm{~cm}$.

No teste de compressão, o grupo II (mesmo diâmetro do osso) apresentou diferença significativa quanto à maior resistência $(\mathrm{P}=0,001)$ quando comparado aos ossos. Considerou-se esse diâmetro como adequado quanto à resistência, evitando-se que a barra ficasse excessivamente grande, volumosa e pesada, com possibilidade de promover melhor recuperação do paciente quando utilizado FEE tipo Ia. Essa observação segue a indicação trazida por Maccoy (1991) e Alievi et al. (2008), os quais descrevem que, quando se utiliza uma barra de conexão leve, evita-se atrofia muscular e peso adicional ao FEE, proporcionando retorno precoce às funções motoras.

No ensaio de flexão, houve diferença significativa, em que o $\mathrm{P}=0,002$ entre os ossos testados com o grupo III. Os ossos tiveram maior resistência do que as barras conectoras com a metade do diâmetro do osso (grupo III), mostrando que esse diâmetro de barra poderia ser insuficiente para sustentar e neutralizar a força de flexão que é gerada na barra conectora. Ross e Matthiesen (1993) citam que a barra conectora de PMMA pode quebrar quando o seu diâmetro for muito pequeno em FEE tipo $\mathrm{Ib}$ ao ser utilizada em estabilização de coluna vertebral em cães, o que ocorre pela movimentação cíclica da coluna. Isso pode ser evitado utilizando-se barras do grupo II, as quais demonstraram ser 4,3 vezes mais resistentes na flexão do que as do grupo III.

\section{CONCLUSÃO}

Com base nos resultados obtidos no presente trabalho, pode-se afirmar que as barras conectoras do mesmo diâmetro do úmero de suínos mostram-se mais resistentes do que os ossos no ensaio de compressão para a configuração tipo Ia. Os resultados deste trabalho poderão auxiliar na padronização das barras de PMMA em relação ao diâmetro e ao comprimento ósseo.

\section{REFERÊNCIAS}

ALIEVI, M.M.; OLIVEIRA, A.N.C. et al. Osteossíntese de úmero em pombos domésticos (Columba livia) associando-se pinos metálicos e polimetilmetacrilato intramedulares após osteotomia diafisária. Arq. Bras. Med. Vet. Zootec., v.60, p.843-850, 2008.

AMENDOLA, G.F. et al. Aspectos biomecânicos compressivos de diáfises femorais caninas conservadas em glicerina a $98 \%$ ou em mel. Cienc. Rural, v.38, p.1341-1345, 2008.

AN, Y.H. et al. Basic concepts of mechanical property measurement and bone biomechanics. In: AN, Y.H.; DRAUGHN, R.A. Mechanical testing of bone and the bone-implant interface. New York: [s.n.], 2000. cap.2, p.23-40.

CASTANIA, V.A. Enxerto córtico-esponjoso honógeno processado quimicamente $e$ esterilizado em óxido de etileno, em cães. 2002. 72f. Dissertação (Mestrado em Cirurgia Veterinária) - Universidade de São Paulo, São Paulo, SP.

CORDEY, J. Introduction: basic concepts and definitions in mechanics. Injury Int. J. Care Injured, v.31, p.1-13, 2000.

COWIN, S.C. Bone poroelasticity - survey article. J. Biomech., v.32, p.217-238, 1999.

DALMOLIN, F. et al. Biomecânica óssea e ensaios biomecânicos - fundamentos teóricos. Cienc. Rural, v.43, p.1675-1682, 2013.

DIAS, L.G.G.G.; PADILHA FILHO, J.G. Dinamização de fixador esquelético externo conectado ao pino intramedular "tie-in" em tíbia de nove cães. Rev. Cient. Eletron. Med. Vet., v.7, p.22-30, 2009.

EGGER, E.L. Fixação esquelética externa. In: SLATTER, D. Manual de cirurgia de pequenos animais. 2.ed. São Paulo: Manole, 1998. v.2, cap. 123, p.1944-1961.

FLO, G.L. et al. Classificação, diagnóstico e tratamento. In: FLO, G.L. et al. Ortopedia $e$ tratamento de fraturas de pequenos animais. 4.ed. Barueri, São Paulo: Manole, 2009. cap.2, p.28-179. 
GARCIA, A. et al. Ensaio de compressão. In: Ensaio dos materiais. Rio de Janeiro: Livros Técnicos e Científicos, 2000a. cap.3, p.44-65.

GARCIA, A. et al. Ensaio de flexão. In: Ensaio dos materiais. Rio de Janeiro: Livros Técnicos e Científicos, 2000b. cap.4, p.66-87.

HULSE, D.; HYMAN, B. Biomecânica e biologia das fraturas. In: SLATTER, D. Manual de cirurgia de pequenos animais. 3.ed. Philadelphia: Saunders, 2003. v.2, cap.126, p.1785-1792.

JOHNSON, A.L. Fundamentos de cirurgia ortopédica e manejo de fraturas. In: FOSSUM, T. W. Cirurgia de pequenos animais. 3.ed. Rio de Janeiro: Elsevier, 2008. cap.31, p.930-1014.

JUDAS, F. et al. Estrutura e dinâmica do tecido ósseo. 2012. 51f. Dissertação (Mestrado em Ortopedia e Traumatologia) - Faculdade de Medicina da Universidade de Coimbra, POR.

MACCOY, D.M. General principles of avian surgery. Comp. Cont. Educ. Pract. Vet., v.13, p.989-992, 1991.

MARCELLIN-LITTLE, D.J. Fixação esquelética externa. In: SLATTER, D. Manual de cirurgia de pequenos animais. 3.ed. Philadelphia: Saunders, 2003. v.2, cap.129, p.1818-1834.

PIERMATTEI, D.L. et al. Fraturas: classificação, diagnóstico e tratamento. In: BRINKER, PIERMATTEI, FLO. Ortopedia $e$ tratamento de fraturas de pequenos animais. 4.ed. São Paulo: Manole, 2006. cap.2, p.28-179.

ROCHA, C.O.J.M. Comparação da avaliação mecânica de compressão axial em seis modelos de fixadores esqueléticos externos confeccionados com barras estabilizadoras de polimetacrilato de metila ou de madeira $e$ parafusos de aço inoxidável 304. 2008. 77f. Dissertação (Mestrado em Ortopedia e Traumatologia) - Curso de Pós-graduação em Medicina Veterinária, Universidade Federal Rural do Rio de Janeiro, Rio de Janeiro, RJ.
ROSS, J.T.; MATTHIESEN. D. The use of multiple pin and methylmethacrylate external skeletal fixation for the treatment of orthopaedic injuries in the dog and cat. In: ROSS, J.T. Veterinary comparative orthopaedics and traumatology. [s.1.]: [s.n.], 1993. cap.6, p.115121.

SCHMAEDECKE, A. Avaliação biomecânica de diferentes bloqueios transcorticais de interlockingnail em relação as forças de torção, encurvamento e axiais atuantes em fraturas diafisárias de fêmur de cães - estudo in vitro. 2007. 144f. Tese (Doutorado em Medicina Veterinária) - Programa de Pós-graduação em Cirurgia Veterinária, Universidade de São Paulo, São Paulo, SP.

SCHWARZ, P.D. Biomecânica das fraturas do esqueleto apendicular: causas e avaliação. In: BOJRAB, M.J. Mecanismos da moléstia na cirurgia dos pequenos animais. 2.ed. São Paulo: Manole, 1996. cap.136, p.1161-1181.

SOUZA, M.M. et al. Análise da resistência mecânica de 13 cimentos ósseos acrílicos. Rev. Bras. Med., v.67, p.15-31, 2010.

SOUZA, R.A. et al. Propriedades mecânicas do tecido ósseo e risco de fraturas. In: ENCONTRO LATINO AMERICANO DE INICIAÇÃO CIENTÍFICA, 9.; ENCONTRO LATINO AMERICANO DE PÓS-GRADUAÇÃO, 5., 2009, São José dos Campos-SP. Anais... São José dos Campos: Universidade do Vale do Paraíba, 2009. 3p

SOUZA, S.A. Ensaios mecânicos de materiais metálicos. 3.ed. São Paulo: Edgard Blucher, 1974. cap.4, p.235-237.

VASSEUR, P.B. Sistema musculoesquelético. In: SLATTER, D. Manual de cirurgia de pequenos animais. 3.ed. Barueri, São Paulo: Manole, 2003. v.2, cap.15, p.1774-1785. 